\title{
Efficacy of Endoscopic Evaluation of Acute Radiation Esophagitis during Chemoradiotherapy with Proton Beam Therapy Boost for Esophageal Cancer
}

\author{
Kenkei Hasatani ${ }^{\mathrm{a}-\mathrm{c}}$ Hiroyasu Tamamurad ${ }^{d}$ Kazutaka Yamamoto $^{d}$ Hiroyuki Aoyagi $^{\mathrm{a}}$ \\ Tamon Miyanaga e Yasuharu Kaizaki ${ }^{f}$ Takeshi Sawadab,c \\ ${ }^{a}$ Department of Gastroenterology, Fukui Prefectural Hospital, Fukui, Japan; ${ }^{b}$ Division of Translational and Clinical \\ Oncology, Cancer Research Institute, Kanazawa University, Kanazawa, Japan; 'Department of Cardiovascular and Internal \\ Medicine, Kanazawa University Graduate School of Medicine, Kanazawa, Japan; d Proton Therapy Center, Fukui Prefectural

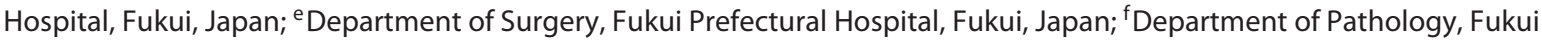 \\ Prefectural Hospital, Fukui, Japan
}

\author{
Keywords \\ Esophageal cancer · Radiation esophagitis - Endoscopic \\ grade Proton beam therapy
}

\begin{abstract}
Background/Aim: To evaluate the utility of endoscopy for assessing radiation esophagitis during chemoradiotherapy (CRT) with proton beam therapy (PBT) boost for esophageal cancer. Methods: Between December 2012 and December 2016, 38 patients with esophageal cancer were treated with CRT with PBT boost. To evaluate radiation esophagitis, endoscopy was performed after administration of CRT with standard PBT boost (total dose 50-60 Gy relative biological effectiveness [RBE]). Radiation esophagitis was evaluated and classified into 5 newly developed endoscopic grades (Fukui Acute Radiation Esophagitis [FARE] grade). The additional PBT boost was then adjusted and delivered (2-20 Gy [RBE]) to a maximum total dose of 74.4 Gy (RBE) based on the degree of radiation esophagitis, probability of residual tumor, and patient's general condition. To evaluate the utility
\end{abstract}

of endoscopic examination, the incidences of adverse events graded according to National Cancer Institute Common Terminology Criteria for Adverse Events (CTCAE, version 4.0) were determined at the time of endoscopic examination after CRT with standard PBT boost (50-60 Gy [RBE]) and at the completion of treatment (60-74.4 Gy [RBE]), as well as during the 90 days from the beginning of treatment. Results: There was a significant correlation between FARE grade and CTCAE esophagitis grade ( $\rho=0.48 ; p=0.03$ ). Moreover, endoscopy detected severe esophagitis in an asymptomatic patient. Radiation dose escalation was achieved without severe acute adverse events. There was no significant difference between the incidence of acute toxicity at the time of the CRT with standard PBT boost (50-60 Gy [RBE]) and the higher dose at the completion of treatment (60-74.4 Gy [RBE]), which suggests this dose escalation strategy is safe. Conclusion: Endoscopic evaluation of radiation esophagitis using FARE grades was safely performed and useful for adjusting added radiation to ensure the safety of escalations in CRT with PBT boost for esophageal cancer.

(c) 2019 The Author(s)

Published by S. Karger AG, Basel

\begin{tabular}{|c|c|c|}
\hline KARGER & $\begin{array}{l}\text { (๔) } 2019 \text { The Author(s) } \\
\text { Published by S. Karger AG, Basel }\end{array}$ & $\begin{array}{l}\text { Karger } \\
\text { Open access }\end{array}$ \\
\hline $\begin{array}{l}\text { karger@karger.com } \\
\text { www.karger.com/dig }\end{array}$ & $\begin{array}{l}\text { This article is licensed under the Creati } \\
\text { NonCommercial-NoDerivatives } 4.0 \text { Inte } \\
\text { NC-ND) (http:///www.karger.com/Ser } \\
\text { Usage and distribution for commercial p p } \\
\text { tribution of modified material requires w }\end{array}$ & $\begin{array}{l}\text { Commons Attribution- } \\
\text { ational License (CC BY- } \\
\text { es/OpenAccessLicense). } \\
\text { poses as well as any dis- } \\
\text { ten permission. }\end{array}$ \\
\hline
\end{tabular}

Takeshi Sawada, MD, PhD

Division of Translational and Clinical Oncology Cancer Research Institute, Kanazawa University

13-1 Takaramachi, Kanazawa 920-8641 (Japan)

E-Mail takeshisawada @ icloud.com 


\section{Introduction}

Esophageal cancer is the sixth leading cause of cancerrelated death worldwide [1]. In recent years, the number of patients diagnosed with early stage disease has been increasing, although most patients are still being diagnosed with advanced disease and have a dismal prognosis. Although the optimal treatment of locally advanced esophageal cancer is neoadjuvant chemoradiotherapy (CRT) followed by surgery [2], this approach is associated with a high morbidity rate, high surgery-related mortality rate, and postoperative decline in the quality of life [1]. On the other hand, there have been advances in definitive concurrent CRT [3], and CRT is currently the standard therapy for unresectable, locally advanced esophageal cancer $[3,4]$.

The most frequent failure after CRT for esophageal cancer is local recurrence [3-6]. It is therefore warranted to explore potential ways of enhancing local control, including dose escalation. The results of one recent randomized trial (RTOG 94-05) indicated that dose escalation from 50.4 to 64.8 Gy was not advantageous with respect to the local/regional control or survival [7]. By contrast, several studies [8-11] report the safety and beneficial effect of dose escalation on treatment outcome and point out the possibility that the boosted irradiation may contribute to the improved tumor control. Nevertheless, dose escalation is challenging because of the central location of the esophagus within the thorax. One must delicately balance minimizing radiation dose to nearby critical structures (i.e., heart, lung, and spinal cord) in addition to the surrounding normal esophageal tissue while maintaining an effectively high dose to the target. Thus, dose escalation must be carefully performed to avoid severe adverse effects.

In patients with thoracic cancers treated with radiotherapy alone or concurrent CRT, radiation esophagitis is a common side effect that adversely affects not only the patient's quality of life but also the therapeutic efficacy by preventing tumor dose escalation and possibly causing treatment interruption [12-14]. Therefore, the accurate evaluation of esophagitis is indispensable for CRT with or without dose escalation. The incidence and degree of radiation esophagitis are generally evaluated based on clinical symptoms, including dysphagia, odynophagia, and chest discomfort (or substernal pain), though several studies have investigated the efficacy of endoscopic evaluation of radiation esophagitis, mainly in patients with lung cancer [15-18]. A standard endoscopic evaluation method for radiation esophagitis has not yet been estab- lished. And given that the clinical symptoms are not always consistent with the endoscopic findings $[15,16]$, endoscopic examination would be useful for the evaluation of mucosal damage and the precise degree of radiation esophagitis.

Recent reports indicate that proton beam therapy (PBT) is an effective treatment for esophageal cancer [1925]. In contrast to conventional radiation therapy, PBT takes advantage of Bragg peak properties to deliver a high radiation dose to the target tumors, while reducing the irradiated volume and radiation dose to the surrounding normal tissue. Nonetheless, previous reports indicate a considerable rate of esophagitis when PBT is combined with chemotherapy for treatment of esophageal cancer $[19,20]$.

In the present study, we hypothesized that endoscopic examination during PBT boost with CRT could be useful for evaluating radiation esophagitis to select patients who would benefit from dose escalation. To test that hypothesis, we examined the safety of dose escalation based on the original endoscopic grade created for more accurate evaluation of radiation esophagitis. Our aim was to evaluate the usefulness of endoscopic assessment of acute radiation esophagitis for safe dose escalation.

\section{Materials and Methods}

\section{Eligibility Criteria}

Between December 2012 and December 2016, 38 patients with esophageal cancer were treated with CRT with PBT boost and met the following eligibility criteria: (1) had a pathologically confirmed diagnosis of squamous cell carcinoma or adenocarcinoma of the esophagus; (2) had 2009 TNM Classification of the Union for International Cancer Control stage I-III disease based on the findings of esophagography, esophagoscopy, plain and contrast-enhanced computed tomography (CT) scan, and/or 18F-fluorodeoxyglucose positron emission tomography (FDG-PET)/CT scan; (3) were over 20 years of age with performance status $0-1$ based on the Eastern Cooperative Oncology Group scale; (4) had adequate organ function, as indicated by a leucocyte count $\geq 4,000 / \mathrm{mm}^{3}$ and $\leq 12,000 / \mathrm{mm}^{3}$, platelet count $\geq 100,000 / \mathrm{mm}^{3}$, hemoglobin level $\geq 10.0 \mathrm{~g} / \mathrm{dL}$, AST and ALT $<100 \mathrm{IU} / \mathrm{L}$, total bilirubin $\leq 2.0 \mathrm{mg} / \mathrm{dL}$, serum creatinine $\leq 1.2 \mathrm{mg} / \mathrm{dL}$, creatinine clearance $\geq 60 \mathrm{~mL} / \mathrm{min}$, and $\mathrm{PaO} 2 \geq 70$ Torr. In surgically resectable cases, we first recommended surgical resection as a standard treatment. Then, patients who refused surgical treatment and patients with surgically unresectable tumors were administered CRT with PBT boost. This study was conducted as a retrospective analysis of prospectively collected data. Informed consent was obtained from all patients before treatment. All patients were approved by a committee of the Fukui Proton Beam Center and the Departments of Gastroenterology, Surgery and Pathology of Fukui Prefectural Hospital (protocol number 14-70). The institutional committee routinely checked all treatment plans before carrying out the actual treatment. 


\begin{tabular}{|c|c|c|c|c|c|c|c|c|c|}
\hline & 1 & 2 & 3 & 4 & 5 & 6 & 7 & 8 & Weeks \\
\hline Endoscopy & & & & & & & & & \\
\hline $\operatorname{CDDP}\left(70 \mathrm{mg} / \mathrm{m}^{2}\right.$, day 1$)$ & & & & & & & & & \\
\hline 5 -FU $\left(700 \mathrm{mg} / \mathrm{m}^{2}\right.$, day $\left.1-4\right)$ & & & & & & & & & \\
\hline X-ray therapy (36-41.4 Gy) & & & & & & & & & \\
\hline $\begin{array}{l}\text { PBT (standard boost) } \\
(10-20 \text { Gy [RBE]) }\end{array}$ & & & & & & & & & \\
\hline $\begin{array}{l}\text { PBT (additional boost) } \\
\text { (2-20 Gy [RBE]) }\end{array}$ & & & & & & & & & \\
\hline Evaluation of toxicities (CTCAE grade) & & & & & & & 0 & & ப \\
\hline
\end{tabular}

Fig. 1. Treatment design. PBT, proton beam therapy; RBE, relative biological effectiveness; CTCAE, Common Terminology Criteria for Adverse Events. (with a 5.8-mm outer diameter), was used transorally if a conventional endoscope could not fit past the tumor because of severe stenosis. Macroscopic findings on endoscopy were classified according to the Japanese Classification of Esophageal Cancer (11th Edition) [26]. Tumors were evaluated based on the circumferential ratio of the tumor to the entire esophagus $(\leq 1 / 4,>1 / 4$ and $\leq 1 / 2$, $>1 / 2$ and $\leq 3 / 4,>3 / 4$ ) and its maximum length (in centimeters). The presence of severe stenosis was also evaluated.

\section{Endoscopic Assessment of Radiation Esophagitis after} Combined Administration of X-Ray Therapy with Standard PBT Boost (50-60 Gy [RBE])

Endoscopy was performed at the time of the combined administration of X-ray therapy and standard PBT boost (a total dose of $50-60 \mathrm{~Gy}[\mathrm{RBE}])$. This endoscopy was done by the same endoscopist who examined the patient before the treatment, and the endoscopic findings were shared with the radiation oncologists. Endoscopic findings were evaluated based on new classification criteria for acute radiation esophagitis created in this study: the Fukui Acute Radiation Esophagitis (FARE) grade. With these criteria, endoscopic findings of esophageal damage were scored 1-5 in the following manner (Table 1; Fig. 2): grade 1, normal-appearing esophageal mucosa or mucosa with erythema; grade 2, mucosa with erosion or contact bleeding; grade 3, mucosa with a shallow ulcer, small amount of spontaneous bleeding (minor); grade 4, mucosa with a deep ulcer, spontaneous bleeding (extensive), stenosis (complete obstruction); grade 5, perforation, fistula, spontaneous bleeding (severe). The mucosal damage was scored for the area with the most remarkable findings. The classification was created such that grades 1 and 2 are states where dose escalation is possible, grade 3 is a state where dose escalation requires caution, grade 4 is a state where dose escalation carries a high level of risk, and grade 5 is a state where dose escalation is not advisable. Because the endoscopist knew the details of patient's clinical symptoms, information bias on endoscopic assessment could be introduced. Therefore, to avoid inter-physician bias, the grade following the examination was determined by referring static images to 5 experts in the Japan Gastroenterological Endoscopy Society, who had no knowledge of the clinical symptoms.

\section{Endoscopic Assessment of the Primary Tumor}

before Treatment

Endoscopic examination was performed to assess the primary tumor prior to treatment. Two models of endoscopes, the OLYMPUS GIF-H260 (with a $9.8-\mathrm{mm}$ outer diameter) and GIF-H260Z (with a 10.8 -mm outer diameter), were primarily used for this examination. A nasal endoscope, the OLYMPUS GIF-XP260NS
Hasatani/Tamamura/Yamamoto/Aoyagi/ Miyanaga/Kaizaki/Sawada 

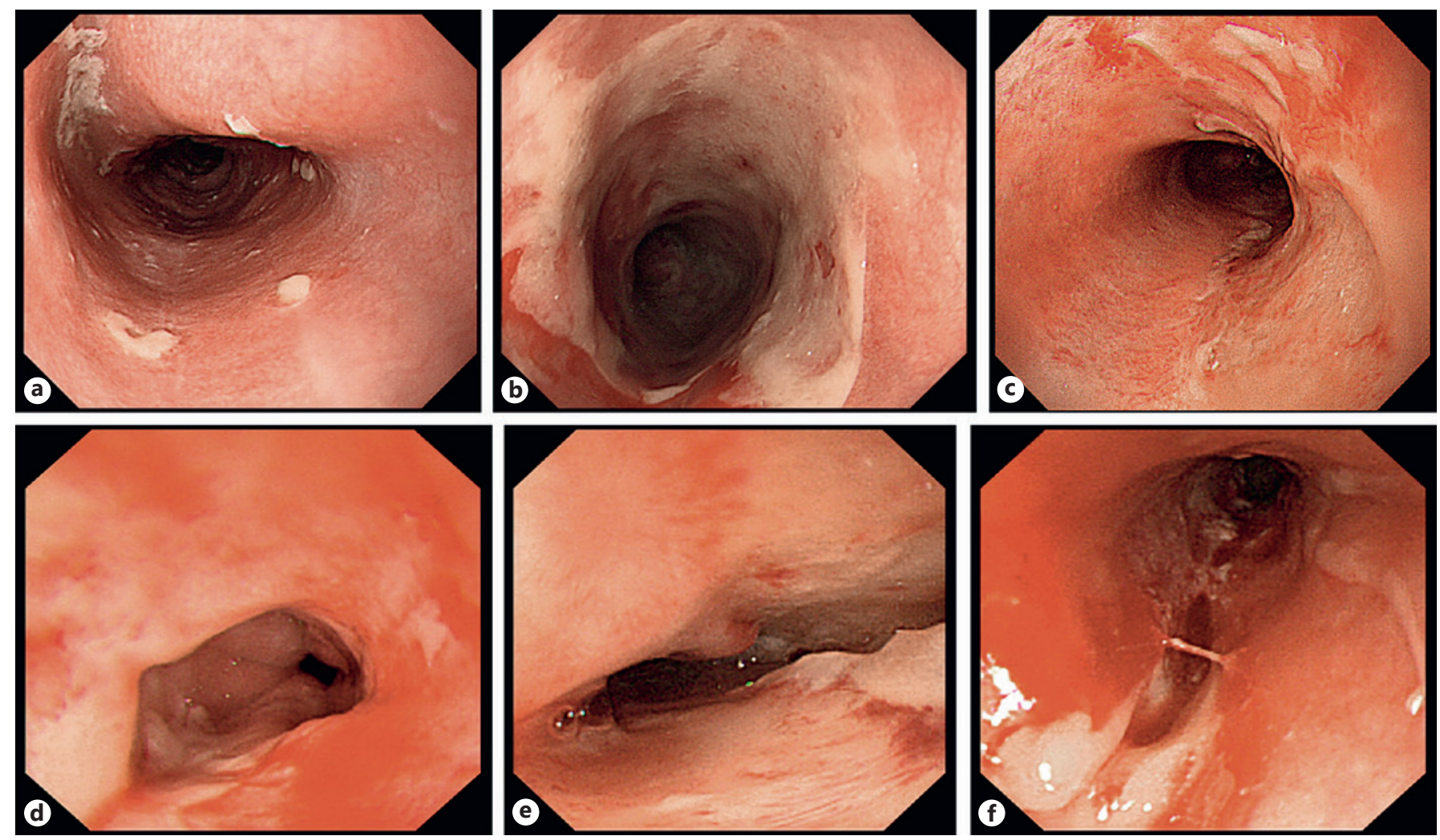

Fig. 2. Representative endoscopic images of acute esophageal injury classified according to its FARE grade. a Mucosa with erythema (grade 1). b Mucosa with erosion (grade 2). c Mucosa with

a shallow ulcer (grade 3). d Minor spontaneous bleeding (grade 3). e Mucosa with a deep ulcer (grade 4). f Extensive spontaneous bleeding (grade 4).

Table 1. New endoscopic grades (FARE grade)

\begin{tabular}{ll}
\hline Endoscopic grade & Findings \\
\hline 1 & Normal mucosa or mucosa with erythema \\
2 & Mucosa with erosion, contact bleeding \\
3 & Mucosa with a shallow ulcer, spontaneous bleeding (minor)* \\
4 & Mucosa with a deep ulcer, spontaneous bleeding (extensive), stenosis (complete obstruction) ${ }^{* *}$ \\
5 & Perforation, fistula, spontaneous bleeding (severe) \\
\hline
\end{tabular}

* Ulceration to the submucosa.

** Ulceration to the muscularis propria

FARE, Fukui Acute Radiation Esophagitis.

Comparison of the FARE Grade and CTCAE

Esophagitis Grade

The symptomatic grade (CTCAE esophagitis grade) was recorded at the time of the endoscopic examination after the combined administration of X-ray therapy and standard PBT boost to a total dose of 50-60 Gy (RBE). The FARE grade was compared with the CTCAE esophagitis grade to assess the correlation between the endoscopic findings and symptoms.

Efficacy of Endoscopic Evaluation of Acute Radiation Esophagitis
Dose escalation Based on Endoscopic Evaluation

Decisions regarding dose escalation were discussed at an institutional conference attended by representatives from the Departments of Gastroenterology, Surgery and Pathology as well as Proton Therapy Center. The additional dose was adjusted based on comprehensive assessment of the FARE grade, the probability of residual disease, and the patient's general condition. 
Table 2. Characteristics of patients enrolled in this study

\begin{tabular}{|c|c|}
\hline \multicolumn{2}{|l|}{ Patients $(n=38)$} \\
\hline Age, years, median (range) & $67(50-81)$ \\
\hline \multicolumn{2}{|l|}{ Gender } \\
\hline Male & 27 \\
\hline Female & 11 \\
\hline \multicolumn{2}{|l|}{ Lesions $(n=38)$} \\
\hline \multicolumn{2}{|l|}{ Location } \\
\hline Cervical esophagus & 2 \\
\hline Upper thoracic esophagus & 4 \\
\hline Middle thoracic esophagus & 25 \\
\hline Lower thoracic esophagus & 6 \\
\hline Abdominal esophagus & 1 \\
\hline \multicolumn{2}{|l|}{ Histology } \\
\hline Squamous cell carcinoma & 37 \\
\hline Adenocarcinoma & 1 \\
\hline \multicolumn{2}{|l|}{ Stage } \\
\hline I & 9 \\
\hline II & 8 \\
\hline III & 21 \\
\hline \multicolumn{2}{|l|}{$\mathrm{T}$ factor } \\
\hline 1 & 9 \\
\hline 2 & 7 \\
\hline 3 & 14 \\
\hline 4 & 8 \\
\hline \multicolumn{2}{|l|}{ Type, $n(\%)$} \\
\hline 0 (I/IIa/IIb/IIc/III) & $9(0 / 5 / 2 / 2 / 0 ; 23.7)$ \\
\hline 1 & $6(15.8)$ \\
\hline 2 & $18(47.4)$ \\
\hline 3 & $4(10.5)$ \\
\hline 4 & $0(0.0)$ \\
\hline 5 & $1(2.6)$ \\
\hline Length, $\mathrm{cm}$, median (range) & $5.5(2-15)$ \\
\hline \multicolumn{2}{|l|}{ Circumference, $n(\%)$} \\
\hline$\leq 1 / 4$ & $5(13.2)$ \\
\hline$>1 / 4$ or $\leq 1 / 2$ & $13(34.2)$ \\
\hline$>1 / 2$ or $\leq 3 / 4$ & $7(18.4)$ \\
\hline$>3 / 4$ & $13(34.2)$ \\
\hline \multicolumn{2}{|l|}{ Stenosis, $n(\%)$} \\
\hline \multicolumn{2}{|l|}{$\begin{array}{l}\text { Passage of the conventional } \\
\text { endoscope }\end{array}$} \\
\hline Yes & $25(65.8)$ \\
\hline No & $13(34.2)$ \\
\hline
\end{tabular}

Comparison of the Incidence of Adverse Events after Administering a Dose of 50-60 Gy (RBE) and at the End of Treatment

First, acute toxicities (esophagitis, hematological toxicities, heart failure, and pulmonary failure) were assessed using CTCAE version 4.0 at the time of endoscopy after 50-60 Gy (RBE) and at the completion of the treatment. We evaluated the safety of dose escalation by comparing the fractions of patients with CTCAE grade 3 or higher toxicities at the 2 time points (Fig. 1). In addition, these toxicities were evaluated during the entire 90 days since the initiation of treatment.

\section{Statistical Analysis}

We used the Spearman rank correlation coefficient $(\rho)$ to assess the correlation between FARE grade and CTCAE esophagitis grade. We used the exact matched-pair method to compare the incidence of adverse events (greater than CTCAE grade 3) after the combined administration of X-ray therapy and standard PBT boost (total dose, 50-60 Gy [RBE]) with the incidence at the completion of treatment. Values of $p<0.05$ were considered statistically significant. Statistical analysis was performed using SAS 9.4 (SAS Institute, Cary, NC, USA).

\section{Results}

\section{Patient Characteristics}

The characteristics of the 38 patients who met the eligibility criteria are listed in Table 2 . The participants included 27 men and 11 women, who had a median age of 67 years (range $50-81$ years). The tumor was located in the cervical esophagus in 2 patients, upper thoracic in 4 patients, middle thoracic in 25 patients, lower thoracic in 6 patients, and abdominal in 1 patient. Histology showed squamous cell carcinomas in 37 patients and adenocarcinoma in 1 patient. Based on Union for International Cancer Control classifications, 9 patients had T1 disease, 7 had T2, 14 had T3, and 8 had T4. In addition, 9 were stage I, 8 were stage II, and 21 were stage III.

\section{Endoscopic Findings for the Primary Tumor \\ before Treatment}

Primary tumors were diagnosed endoscopically as Type 0-IIa $(n=5), 0$-IIb $(n=2), 0$-IIc $(n=2), 1(n=6)$, $2(n=18), 3(n=4)$, or $5(n=1)$. The median maximum length was $5.5 \mathrm{~cm}$ (range $2-15 \mathrm{~cm}$ ), and the circumferential ratio of the tumor to the entire esophagus was $\leq 1 / 4$ in 5 patients, $>1 / 4$ and $\leq 1 / 2$ in 13 patients, $>1 / 2$ and $\leq 3 / 4$ in 7 patients, and $>3 / 4$ in 13 patients. Severe stenosis that a conventional endoscope could not get past was present in 13 patients (34.2\%; Table 2 ).

\section{Endoscopic Findings for Radiation Esophagitis after Combined Administration of X-Ray Therapy with \\ Standard PBT Boost (50-60 Gy [RBE])}

Endoscopic esophagitis grade (FARE grade) after combined administration of X-ray therapy with standard PBT boost (50-60 Gy [RBE]) was grade 1 in 3 patients (7.9\%), grade 2 in 24 patients (63.2\%), grade 3 in 10 patients (26.3\%), grade 4 in 1 patient (2.6\%), and grade 5 in 0 patients $(0 \%$; Table 3$)$. Endoscopy revealed ulceration to the muscular layer in the grade 4 patient. There were no patients with a perforation or fistula. 


\section{Correlation between FARE Grade and CTCAE Esophagitis Grade}

Table 3 shows the correlation between the FARE grade and CTCAE esophagitis grade after administration of $\mathrm{X}$-ray therapy and standard PBT boost to a total radiation dose of 50-60 Gy (RBE). The Spearman rank correlation coefficient $(\rho)$ was $0.48(p=0.03)$, indicating a statistically significant difference (Table 3 ).

\section{Dose Escalation Based on Endoscopic Evaluation}

Among the 38 participants, the median total radiation dose was 66.3 Gy (RBE; range 60-74.4; proton 20-38). There were 3 patients $(7.9 \%)$ with a FARE grade 1,24 (63.2\%) with FARE grade 2, 10 (26.3\%) with a FARE grade 3 , and $1(2.6 \%)$ with a FARE grade 4 . Among those 4 groups, the median total radiation dose was 70 Gy (RBE), $67.4 \mathrm{~Gy}(\mathrm{RBE}), 66 \mathrm{~Gy}$ (RBE) and $62 \mathrm{~Gy}(\mathrm{RBE})$ respectively (Table 4).

\section{Acute Toxicities during Treatment}

Data on the adverse events (CTCAE version 4.0) for all 38 patients during the 90 days from the beginning of treatment are summarized in Table 5. Grade 3 esophagitis, leukopenia, neutropenia, anemia, and thrombocytopenia were observed in $26.3,44.7,31.6,7.9$, and $7.9 \%$ of patients respectively. No patients experienced greater than or equal to grade 3 heart failure or respiratory failure.

Comparison between the Incidences of Adverse Events after Combined Administration of X-Ray Therapy and Standard PBT Boost (50-60 Gy [RBE]) and at the Completion of Treatment (60-74.4 Gy [RBE])

There was no significant difference between the incidences of esophagitis with a CTCAE grade of 3 or higher after combined administration of X-ray therapy and standard PBT boost (50-60 Gy [RBE]) and at the completion of treatment (60-74.4 Gy [RBE]). Moreover, there was no significant difference in the incidences of hematological toxicity (Table 6).

\section{Discussion}

In the present study, endoscopic evaluation of radiation esophagitis after combined administration of X-ray therapy with standard PBT boost was safely performed and was useful for dose escalation in CRT with PBT boost for esophageal cancer. Although there have been a few studies in which the extent of radiation esophagitis
Table 3. Correlation between FARE grade and CTCAE esophagitis grade after administration of a total radiation dose of 50-60 Gy $(\mathrm{RBE})$

\begin{tabular}{llllll}
\hline \multirow{2}{*}{$\begin{array}{l}\text { FARE } \\
\text { grade }\end{array}$} & \multirow{2}{*}{$\begin{array}{l}\text { Number } \\
\text { of patients }\end{array}$} & \multicolumn{4}{c}{ CTCAE esophagitis grade } \\
\cline { 3 - 5 } & & 1 & 2 & 3 & 4 \\
\hline 1 & 3 & 1 & 1 & 1 & 0 \\
2 & 24 & 9 & 12 & 3 & 0 \\
3 & 10 & 1 & 4 & 5 & 0 \\
4 & 1 & 0 & 0 & 1 & 0 \\
5 & 0 & 0 & 0 & 0 & 0 \\
\hline
\end{tabular}

Spearman rank correlation coefficient $(\rho)=0.48 ; p=0.03$.

FARE, Fukui Acute Radiation Esophagitis; CTCAE, Common Terminology Criteria for Adverse Events; RBE, relative biological effectiveness.

Table 4. Dose escalation by endoscopic evaluation of radiation esophagitis and residual tumor

\begin{tabular}{lcc}
\hline FARE grade & Number $(\%)$ & Total dose (Gy [RBE]), (range) \\
\hline 1 & $3(7.9)$ & $70(60-73.4)$ \\
2 & $24(63.2)$ & $67.4(60-74.4)$ \\
3 & $10(26.3)$ & $66(60-67.4)$ \\
4 & $1(2.6)$ & $62(62)$ \\
5 & $0(0)$ & - \\
\hline
\end{tabular}

FARE, Fukui Acute Radiation Esophagitis; RBE, relative biological effectiveness.

Table 5. Acute toxicities in 38 patients receiving CRT with proton beam therapy

\begin{tabular}{lcll}
\hline Toxicities, $n(\%)$ & Grade 3 & Grade 4 & Grade 5 \\
\hline Non-hematologic & & & \\
$\quad$ Esophagitis & $10(26.3)$ & 0 & 0 \\
$\quad$ Heart failure & 0 & 0 & 0 \\
$\quad$ Respiratory failure & 0 & 0 & 0 \\
Hematologic & $17(44.7)$ & 0 & 0 \\
$\quad$ Leukopenia & $12(31.6)$ & 0 & 0 \\
$\quad$ Neutropenia & $3(7.9)$ & 0 & 0 \\
$\quad$ Anemia & $3(7.9)$ & 0 & 0 \\
$\quad$ Thrombocytopenia & & & \\
\hline CRT, chemoradiotherapy. &
\end{tabular}


Table 6. Treatment-related toxicities after a radiation dose of 50-60 Gy (RBE) and at the end of treatment

\begin{tabular}{|c|c|c|c|c|}
\hline \multirow[t]{2}{*}{ Adverse event } & \multicolumn{3}{|c|}{ Number of patients with adverse effect (grades 3 and 4) } & \multirow[t]{2}{*}{$p$ value } \\
\hline & $\begin{array}{l}\text { both radiation dose of } 50-60 \\
\text { Gy }(\mathrm{RBE}) \text { and end of treatment }\end{array}$ & $\begin{array}{l}\text { at the time of endoscopy } \\
(50-60 \mathrm{~Gy}[\mathrm{RBE}])\end{array}$ & end of treatment & \\
\hline \multicolumn{5}{|l|}{ Non-hematologic } \\
\hline Esophagitis & 10 & 10 & 10 & 1.00 \\
\hline \multicolumn{5}{|l|}{ Hematologic } \\
\hline Anemia & 3 & 1 & 3 & 0.63 \\
\hline Thrombocytopenia & 1 & 1 & 1 & 1.00 \\
\hline
\end{tabular}

was evaluated using CT [27] or FDG-PET/CT [28] in the treatment of lung cancer, no standard modality has been established for assessing radiation esophagitis occurring with CRT, and grading was based mainly on the patient's symptoms. Particularly for patients with esophageal cancer, endoscopy is considered to be a more useful modality than CT or FDG-PET/CT because esophagitis and primary tumors can be separately evaluated. An endoscopic grading system for radiation esophagitis was proposed by Kuwahata in 1980 (in Japanese with English abstract) [15], and several groups have used this system to evaluate radiation esophagitis [15-17]. However, conditions such as perforation and fistula formation, which make continued treatment difficult, were not considered in that endoscopic grading system; nor were the extent of ulceration and hemorrhage, which is useful information when considering dose escalation. We therefore created the FARE grade, which is a more extensive endoscopic classification that includes perforation, fistula formation, estimated depth of ulcers and the extent of hemorrhage.

In the present study, we detected a moderate correlation between the FARE grade and CTCAE esophagitis grade at a total dose of 50-60 Gy (RBE) in esophageal cancer patients treated with CRT combined with standard PBT boost (with FP regimen). Similarly, in previous studies $[15,16]$, a correlation between symptomatic and endoscopic scores (Kuwahata's score) was detected, although patients with thoracic malignancies other than esophageal cancer were also included, and the treatments included radiotherapy alone and various types of CRT. In contrast, Koc and Onuk [17] reported that there is no correlation between endoscopic and symptomatic grade after treatment of radiation esopha- gitis. Because esophagitis symptoms such as odynophagia and chest discomfort can also occur due to gastroesophageal reflux disease and Candida infection [18] and are influenced by analgesics and treatment of radiation esophagitis [16], the presence or absence of a correlation may also reflect these factors in addition to the differences in patient characteristics and treatment regimen.

Notably, Hirota et al. [16] reported a discrepancy between esophagitis symptoms and endoscopic findings. In their report, endoscopy revealed erosion or thickly coated ulcers in patients with no symptoms or only mild symptoms. In our study, an ulcer reaching the submucosa (FARE grade 3 ) was seen in an asymptomatic patient (CTCAE esophagitis grade 1). Conversely, FARE grade 1 esophagitis (mucosa with erythema) was present in a patient with severe odynophagia requiring total parenteral nutrition (CTCAE esophagitis grade 3; Table 3 ). Because symptomatic grading does not always accurately reflect mucosal injury in radiation esophagitis $[16,17]$, we suggest that endoscopic examination is preferable for assessing the extent of mucosal injury due to radiation esophagitis and for excluding infection or cancer.

Although there have been several reports of radiation dose escalation attempts in cases of primary esophageal cancer $[9,10]$, there have been no reports in which patients that require dose escalation were selected based on their condition. We attempted to select the patients and regulate additional radiation doses up to a maximum of 74.4 Gy (RBE) based mainly on endoscopic evaluation of the degree of radiation esophagitis prior to termination of therapy, when the total dose was 50-60 Gy (RBE). With respect to acute toxicity, there was no statistically 
significant increase in adverse events between a dose of 50-60 Gy (RBE) and the higher dose at the completion of treatment (60-74.4 Gy [RBE]). This suggests the dose escalation strategy is a safe one. Consistent with that idea, the observed incidence of adverse events with a CTCAE esophagitis grade $>3$ was comparable to those reported in earlier studies in which PBT was combined with chemotherapy, but without dose escalation $[19,20]$. Additionally, although the incidence of grades 3-4 esophagitis in a study of CRT combined with PBT (10.6\%) was lower than that of our study (26.3\%) [25], there was no significant difference between these 2 studies. This discrepancy is probably due to differences of the chemotherapy regimen and patient cohort. Taken together, these results are indicative of the safety of this dose escalation strategy.

In the present study, dose modification was not based solely on the degree of radiation esophagitis. Other factors considered included the probability of residual tumors also assessed endoscopically, patient's age, symptoms, general condition, and the extra-esophageal complications associated with treatment. However, the FARE grade appears to be an effective means of safely escalating dose. In addition, by providing prior understanding of which patients are at higher risk during dose escalation (information that can be shared with the patients), the FARE grade can provide the basis for more careful observations and rapid management of adverse events. Furthermore, if spatial localization of esophagitis is possible with recently developed endoscopy-CT registration system [29], it might be able to correlate this information into the treatment planning process in the future.

Our study has a number of limitations, including its retrospective design, relatively small number of patients, and a short observation period without information on long-term outcomes and toxicities. Nonetheless, we were able to make several important observations. First, endoscopic examination during CRT with PBT boost can be safely performed, and there is a correlation between our new endoscopic grade (FARE grade) and symptomatic grade (CTCAE esophagitis grade). Second, endoscopy could detect severe esophagitis, even in an asymptomatic patient. Third, endoscopy was useful for adjusting the additional radiation dose to ensure the safety of the escalation. To establish personalized treatment strategies and define their clinical role in radiation therapy for esophageal cancer, further study through accumulation of a larger body of cases for this method is warranted.

Efficacy of Endoscopic Evaluation of Acute Radiation Esophagitis

\section{Conclusion}

Endoscopic evaluation of radiation esophagitis using a FARE grade correlated with symptomatic grade (CTCAE grade) and was useful for adjusting the added radiation to ensure the safety of CRT with PBT boost for esophageal cancer.

\section{Acknowledgments}

The authors thank Dr. Ryota Niikura who contributed to statistical review. The authors also thank Dr. William F. Goldman for editing the manuscript.

\section{Statement of Ethics}

Subjects have given their written informed consent. The study protocol has been approved by the research institute's committee on human research.

\section{Disclosure Statement}

The authors declare that they have no conflicts of interest to disclose.

\section{Funding Sources}

No funding was received for this study.

\section{Author Contribution}

K.H., H.T., and K.Y.: designed the study. K.H., H.A., H.T., K.Y., T.M., and Y.K.: acquired data. K.H.: analyzed the data. K.H. and T.S.: wrote the paper; all authors read and gave approval of the final version of the article to be published.

References

1 Pennathur A, Gibson MK, Jobe BA, Luketich JD. Oesophageal carcinoma. Lancet. 2013 Feb;381(9864):400-12.

2 van Hagen P, Hulshof MC, van Lanschot JJ, Steyerberg EW, van Berge Henegouwen MI, Wijnhoven BP, et al.; CROSS Group. Preoperative chemoradiotherapy for esophageal or junctional cancer. N Engl J Med. 2012 May; 366(22):2074-84.

3 Cooper JS, Guo MD, Herskovic A, Macdonald JS, Martenson JA Jr, Al-Sarraf M, et al.; Radiation Therapy Oncology Group. Chemoradiotherapy of locally advanced esophageal cancer: long-term follow-up of a prospective randomized trial (RTOG 85-01). JAMA. 1999 May;281(17):1623-7. 
4 Kato K, Muro K, Minashi K, Ohtsu A, Ishikura S, Boku N, et al.; Gastrointestinal Oncology Study Group of the Japan Clinical Oncology Group (JCOG). Phase II study of chemoradiotherapy with 5-fluorouracil and cisplatin for Stage II-III esophageal squamous cell carcinoma: JCOG trial (JCOG 9906). Int J Radiat Oncol Biol Phys. 2011 Nov;81(3):684-90.

5 Welsh J, Settle SH, Amini A, Xiao L, Suzuki A, Hayashi Y, et al. Failure patterns in patients with esophageal cancer treated with definitive chemoradiation. Cancer. 2012 May;118(10): 2632-40.

6 Kim HW, Kim JH, Lee IJ, Kim JW, Lee YC, Lee CG, et al. Local control may be the key in improving treatment outcomes of esophageal squamous cell carcinoma undergoing concurrent chemoradiation. Digestion. 2014; 90(4):254-60.

7 Minsky BD, Pajak TF, Ginsberg RJ, Pisansky TM, Martenson J, Komaki R, et al. INT 0123 (Radiation Therapy Oncology Group 94-05) phase III trial of combined-modality therapy for esophageal cancer: high-dose versus standard-dose radiation therapy. J Clin Oncol. 2002 Mar;20(5):1167-74.

8 He L, Allen PK, Potter A, Wang J, Chang JY, Gomez DR, et al. Re-evaluating the optimal radiation dose for definitive chemoradiotherapy for esophageal squamous cell carcinoma. J Thorac Oncol. 2014 Sep;9(9):1398-405.

$9 \mathrm{Yu} \mathrm{W}$, Cai XW, Liu Q, Zhu ZF, Feng W, Zhang Q, et al. Safety of dose escalation by simultaneous integrated boosting radiation dose within the primary tumor guided by (18) FDG-PET/CT for esophageal cancer. Radiother Oncol. 2015 Feb;114(2):195-200.

10 Chen J, Guo H, Zhai T, Chang D, Chen Z, Huang $R$, et al. Radiation dose escalation by simultaneous modulated accelerated radiotherapy combined with chemotherapy for esophageal cancer: a phase II study. Oncotarget. 2016 Apr;7(16):22711-9.
11 Vosmik M, Petera J, Sirak I, Hodek M, Paluska P, Dolezal J, et al. Technological advances in radiotherapy for esophageal cancer. World J Gastroenterol. 2010 Nov;16(44):5555-64.

12 Chowhan NM. Injurious effects of radiation on the esophagus. Am J Gastroenterol. 1990 Feb;85(2):115-20.

13 Werner-Wasik M, Yorke E, Deasy J, Nam J, Marks LB. Radiation dose-volume effects in the esophagus. Int J Radiat Oncol Biol Phys. 2010 Mar;76(3 Suppl):S86-93.

14 Baker S, Fairchild A. Radiation-induced esophagitis in lung cancer. Lung Cancer (Auckl). 2016 Oct; 7:119-27.

15 Kuwahata N. The clinical investigation of radiation esophagitis [in Japanese with English abstract]. Kagoshima Daigaku Igaku Zasshi. 1980 Dec;32(3):281-307.

16 Hirota S, Tsujino K, Hishikawa Y, Watanabe $\mathrm{H}$, Kono K, Soejima T, et al. Endoscopic findings of radiation esophagitis in concurrent chemoradiotherapy for intrathoracic malignancies. Radiother Oncol. 2001 Mar;58(3): 273-8.

17 Koc M, Onuk MD. No correlation between endoscopic and symptomatic scoring systems after the treatment of radiation esophagitis. Radiother Oncol. 2002 Feb;62(2):243-4.

18 Perez RA, Early DS. Endoscopy in patients receiving radiation therapy to the thorax. Dig Dis Sci. 2002 Jan;47(1):79-83.

19 Ishikawa H, Hashimoto T, Moriwaki T, Hyodo I, Hisakura K, Terashima H, et al. Proton beam therapy combined with concurrent chemotherapy for esophageal cancer. Anticancer Res. 2015 Mar;35(3):1757-62.

20 Lin SH, Komaki R, Liao Z, Wei C, Myles B, Guo X, et al. Proton beam therapy and concurrent chemotherapy for esophageal cancer. Int J Radiat Oncol Biol Phys. 2012 Jul; 83(3):e345-51.

21 Sugahara S, Tokuuye K, Okumura T, Nakahara A, Saida Y, Kagei K, et al. Clinical results of proton beam therapy for cancer of the esophagus. Int J Radiat Oncol Biol Phys. 2005 Jan;61(1):76-84.

22 Mizumoto $M$, Sugahara S, Nakayama $H$, Hashii H, Nakahara A, Terashima $\mathrm{H}$, et al. Clinical results of proton-beam therapy for locoregionally advanced esophageal cancer. Strahlenther Onkol. 2010 Sep;186(9):482-8.

23 Makishima $\mathrm{H}$, Ishikawa $\mathrm{H}$, Terunuma $\mathrm{T}$, Hashimoto T, Yamanashi K, Sekiguchi T, et al. Comparison of adverse effects of proton and X-ray chemoradiotherapy for esophageal cancer using an adaptive dose-volume histogram analysis. J Radiat Res (Tokyo). 2015 May;56(3):568-76.

24 Chuong MD, Hallemeier CL, Jabbour SK, Yu J, Badiyan S, Merrell KW, et al. Improving outcomes for esophageal cancer using proton beam therapy. Int J Radiat Oncol Biol Phys. 2016 May;95(1):488-97.

25 Takada A, Nakamura T, Takayama K, Makita C, Suzuki M, Azami Y, et al. Preliminary treatment results of proton beam therapy with chemoradiotherapy for stage I-III esophageal cancer. Cancer Med. 2016 Mar;5(3): 506-15.

26 Japan Esophageal Society. Japanese classification of esophageal cancer, 11th edition: part II and III. Esophagus. 2017;14(1):37-65.

27 Niedzielski JS, Yang J, Stingo F, Martel MK, Mohan R, Gomez DR, et al. Objectively quantifying radiation esophagitis with novel computed tomography-based metrics. Int J Radiat Oncol Biol Phys. 2016 Feb;94(2):385-93.

28 Niedzielski JS, Yang J, Liao Z, Gomez DR, Stingo F, Mohan R, et al. (18)F-fluorodeoxyglucose positron emission tomography can quantify and predict esophageal injury during radiation therapy. Int J Radiat Oncol Biol Phys. 2016 Nov;96(3):670-8.

29 Ingram WS, Yang J, Beadle BM, Wendt R 3rd, Rao A, Wang XA, et al. The feasibility of endoscopy-CT image registration in the head and neck without prospective endoscope tracking.PLoSOne.2017May;12(5):e0177886. 